Danko Ćorić

Lidija Ćurković

Marijana Majić Renjo

DOI: $10.21278 /$ TOF.41201

ISSN 1333-1124

eISSN 1849-1391

\title{
STATISTICAL ANALYSIS OF VICKERS INDENTATION FRACTURE TOUGHNESS OF Y-TZP CERAMICS
}

\begin{abstract}
Summary
The purpose of this study was to investigate and analyse the fracture toughness of yttria stabilized tetragonal zirconia polycrystal (Y-TZP) dental ceramics by means of the Vickers indentation technique. Fracture toughness was analysed under the following loads: $29.42 \mathrm{~N}$, $49.03 \mathrm{~N}, 196.13 \mathrm{~N}$, and $294.20 \mathrm{~N}$. Cracks that had developed from the vertices of a Vickers indentation were measured and used for the determination of fracture toughness by using nine different models. It was found that fracture toughness depends on the indentation load, the morphology of indentation cracking, and the applied model of fracture resistance. The set of fracture toughness data was analysed using the two-parameter Weibull statistics. The Weibull modulus and the scale parameter were determined by the linear regression method. It was concluded that the Weibull distribution can describe the fracture toughness of Y-TZP ceramics properly.
\end{abstract}

Key words: $\quad$ Y-TZP ceramics, Indentation test, Fracture toughness, Weibull statistics

\section{Introduction}

The application of ceramics as structural materials is based on their high hardness combined with high temperature resistance and stiffness (modulus of elasticity), chemical inertness, and superior wear resistance. The main goal of the current research is to produce tough, strong and reliable ceramics. However, fracture toughness of ceramics is still poor in comparison with metals and composites. Furthermore, data on fracture toughness properties of ceramics are usually scattered. Therefore, it is necessary to include a statistical analysis in the mechanical characterization of ceramic materials. Zirconia ceramics have received considerable attention in the last decades because of their ability to obtain relatively high fracture toughness values through induced microstructural and phase changes $[1,2]$. This ability is related to the stress-induced phase transformation to monoclinic symmetry $(\mathrm{t} \rightarrow \mathrm{m})$ that tetragonal zirconia may undergo. Such phase transformation involves a volumetric increase $(\sim 4 \%)$ that may induce compressive stresses in the crack area; this prevents crack propagation and thus increases fracture toughness [3]. This strengthening mechanism known as the transformation toughening makes $\mathrm{ZrO}_{2}$ much tougher than all other ceramic materials [1,4-9]. The fracture resistance of ceramics is usually characterized by the mode I fracture 
toughness [10-12]. The concept of fracture toughness, $K_{\text {Ic }}$, is derived from the linear elastic fracture mechanics (LEFM). The stress intensity factor, $K$, represents the magnitude of the stress field in the crack tip region. The index I refers to the tensile or the opening mode, as opposed to the shear mode specified by indices II and III. Thus, the variable known as fracture toughness, $K_{\text {Ic }}$, refers to the critical value of the stress intensity factor in the opening mode with unstable crack propagation.

There are several conventional techniques of fracture toughness measurement, but they are not suitable for everyday testing because they require relatively large samples, sophisticated equipment, and high-precision measurement of crack propagation. A method that is frequently used to determine the fracture toughness of all brittle materials, including ceramics, is the so-called Vickers indentation fracture (VIF) toughness test [13-18]. The method consists of measuring the total length of cracks emanating from the four vertices of a Vickers indentation as a consequence of applied load. The crack lengths are in inverse proportion to the toughness of the material. By measuring the crack lengths, one can determine the fracture toughness $K_{\text {Ic }}$. Advantages of the VIF technique are: (i) only a small volume of material is required, (ii) minimal sample preparation, (iii) low costs, and (iv) simple experimental procedure. Nowadays, there are more than 30 different equations for the determination of fracture toughness by the VIF method. Scientists have been using numerous equations for Palmqvist and / or radial-median cracks (Fig. 1) at the same time, which has resulted in different data for the same material and test conditions. Therefore, it is necessary to identify the crack profile and to select an appropriate equation (model) for obtaining accurate fracture toughness values.
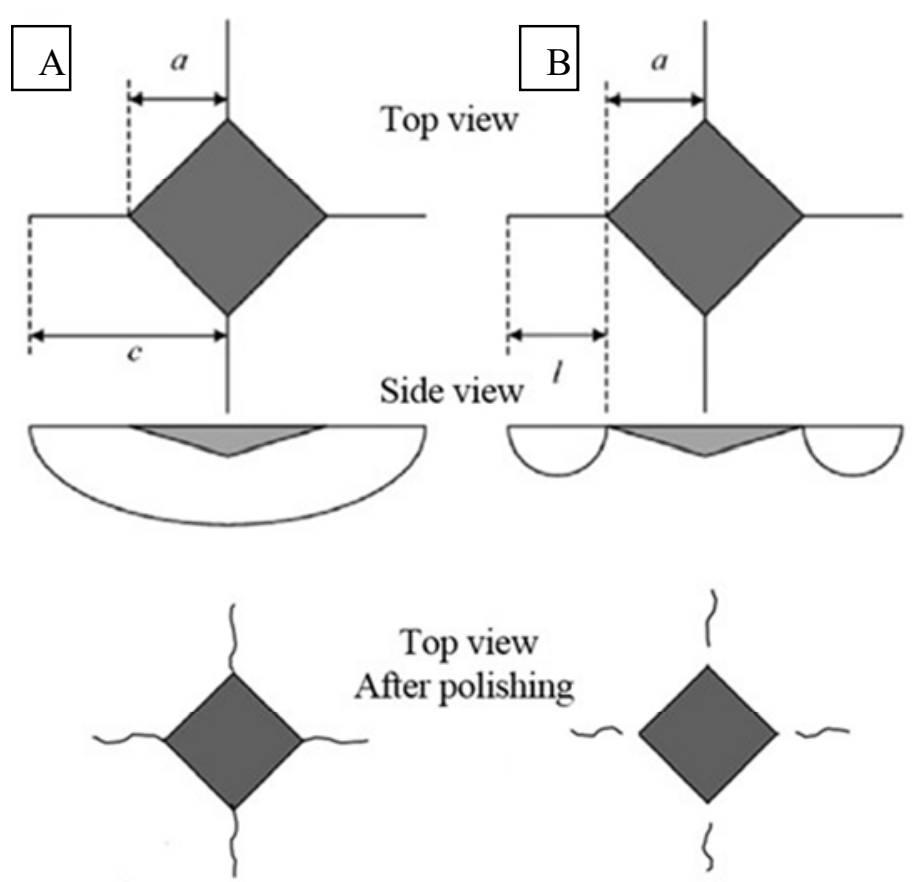

Fig. 1 Cracks emanating from a Vickers indentation, (A) radial-median crack, (B) Palmqvist crack [19]

The goal of this study was to investigate the type of cracking and to evaluate the indentation fracture toughness $\left(K_{\mathrm{Ic}}\right)$ of Y-TZP dental ceramics by using nine different equations at four indentation loads. The gathered data was analysed with the two-parameter Weibull distribution. 


\section{Experiment}

All experiments were performed on the Y-TZP dental ceramics with 4.1 wt. $\% \mathrm{Y}_{2} \mathrm{O}_{3}$. Samples were provided by BruxZir, Glidewell Laboratories (Newport Beach, CA, USA). The manufacturer provided the samples in the shape of square plates, $10 \times 10 \times 2 \mathrm{~mm}$, sintered by the usual sintering regime used in the production of ceramic restorations at the Glidewell Laboratories. The chemical composition of the investigated Y-TZP dental ceramics, according to the manufacturer's declaration, is shown in Table 1.

Table 1 Chemical composition of the Y-TZP dental ceramics expressed as weight percent (wt. \%)

\begin{tabular}{|c|c|c|c|c|c|c|}
\hline \multicolumn{7}{|c|}{ wt. \% } \\
\hline $\mathrm{Y}_{2} \mathrm{O}_{3}$ & $\mathrm{HfO}_{2}$ & $\mathrm{Al}_{2} \mathrm{O}_{3}$ & $\mathrm{SiO}_{2}$ & $\mathrm{Fe}_{2} \mathrm{O}_{3}$ & $\mathrm{Na}_{2} \mathrm{O}$ & $\mathrm{ZrO}_{2}$ \\
\hline 4.1 & 4.0 & 0.34 & $<0.01$ & $<0.01$ & $<0.01$ & Balance \\
\hline
\end{tabular}

The microstructure and the average grain size of the Y-TZP dental ceramics were determined by means of the scanning electron microscopy, using a Tescan Vega TS5136MM (Tescan Orsay Holding, a.s., Czech Republic). The grain size of the sintered Y-TZP dental ceramics was evaluated by the linear intercept method on a scanning electron micrograph of samples that were polished and thermally etched in air at $1480{ }^{\circ} \mathrm{C}$ for $12 \mathrm{~min}$, according to ASTM E112 - 13 standards [20].

Determining the fracture toughness by the Vickers indentation technique and measuring the Vickers hardness require a high quality sample surface. The preparation of the surface prior to hardness measurements affects the hardness and fracture toughness values [21-23]. Therefore, it is important to adequately prepare the sample surface by grinding and polishing, according to the standard ceramographic procedure. First, the samples were polished with a series of diamond pastes up to $1 \mu \mathrm{m}$ finish. The polished sample surface was then penetrated by a Vickers pyramidal indenter to create a deformed region beneath and in the vicinity of the indentation, generating cracks from the vertices of the square Vickers indentation. Fracture toughness determination and hardness measurement were performed under the following loads: $29.42 \mathrm{~N}(H V 3), 49.03 \mathrm{~N}(H V 5), 196.13 \mathrm{~N}(H V 20)$, and $294.20 \mathrm{~N}$ (HV30). The indentations were made under ambient laboratory conditions by means of a hardness tester (Indentec, type: 5030 TKV; Indentec Hardness Testing Machines Ltd., Brierley Hill, UK), while the indentation diagonal and the cracks were measured using an Olympus GX51F-5 optical microscope (Olympus Imaging Corp., Tokyo, Japan) immediately after unloading. Thirty indentations per each load value were performed. The length of cracks, the applied load, the indentation size, the hardness and elastic modulus of the material as well as an empirical calibration constant are used to calculate the indentation fracture toughness using different models. These models were proposed by Casellas, Palmqvist, Shetty et al., Niihara et al., Anstis, Evans and Charles, Tanaka, Lankford, and Niihara, Morena and Hasselman, Table 2.

The set of fracture toughness data was analysed using the two-parameter Weibull statistics. The Weibull function is generally applied to describe the statistical behaviour of mechanical properties of many materials, such as advanced ceramics, glass, and composites with different matrices (metallic, ceramic or polymeric) [24-26]. Several procedures for the calculation of Weibull parameters are known. The Weibull plot (linear-regression method) is the most common one [27-30]. The two-parameter continuous probability density function for the examined variable is given by the following equation:

$$
P=\left(\frac{m}{K_{\text {Ic } 0}}\right)\left(\frac{K_{\text {Ic }}}{K_{\text {Ic } 0}}\right)^{m-1} \exp \left[-\left(\frac{K_{\text {Ic }}}{K_{\text {Ic } 0}}\right)^{\mathrm{m}}\right]
$$


The density function is asymmetrical around the mean value and will assume only positive values. The symbol $m$ is the Weibull modulus, while $K_{\text {Ic } 0}$ is the scale parameter.

Table 2 Equations used in the evaluation of indentation fracture toughness

\begin{tabular}{|c|c|c|}
\hline $\begin{array}{l}\text { Eq. } \\
\text { No. }\end{array}$ & Equation & Author \\
\hline \multicolumn{3}{|c|}{ Palmqvist crack system } \\
\hline$(2)$ & $K_{I C}=0.024 \cdot \frac{F}{c^{3 / 2}} \cdot\left(\frac{E}{H V}\right)^{1 / 2}$ & Casellas $[18,21]$ \\
\hline$(3)$ & $K_{I c}=0.028 \cdot H V^{1 / 2} \cdot\left(\frac{F}{T}\right)^{1 / 2}$ & Palmqvist [31] \\
\hline$(4)$ & $K_{I c}=0.0319 \cdot \frac{F}{a \cdot l^{1 / 2}}$ & Shetty et al. [19] \\
\hline$(5)$ & $K_{I c}=0.0089 \cdot\left(\frac{E}{H V}\right)^{2 / 5} \cdot \frac{F}{a \cdot l^{1 / 2}} \quad$ for $0,25<l / a<2,5$ & Niihara et al. [19] \\
\hline \multicolumn{3}{|c|}{ Radial-median crack system } \\
\hline$(6)$ & $K_{I C}=0.016 \cdot \frac{F}{c^{3 / 2}} \cdot\left(\frac{E}{H V}\right)^{1 / 2}$ & Anstis $[13,15,21]$ \\
\hline$(7)$ & $K_{I c}=0.0752 \cdot \frac{F}{c^{3 / 2}}$ & Evans and Charles [15] \\
\hline$(8)$ & $K_{I c}=0.0725 \cdot \frac{F}{c^{3 / 2}}$ & Tanaka [15] \\
\hline$(9)$ & $K_{I C}=0.0309 \cdot\left(\frac{E}{H V}\right)^{2 / 5} \cdot \frac{F}{c^{3 / 2}}$ & $\begin{array}{l}\text { Niihara, Morena and } \\
\text { Hasselman [22] }\end{array}$ \\
\hline \multicolumn{3}{|c|}{ Crack system of any kind } \\
\hline (10) & $K_{I c}=0.0782 \cdot\left(H V \cdot a^{1 / 2}\right) \cdot\left(\frac{E}{H V}\right)^{2 / 5} \cdot\left(\frac{c}{a}\right)^{-1.56}$ & Lankford [19] \\
\hline
\end{tabular}

The symbols used in Table 2 are as follows: $F$, the applied load during the Vickers test $(\mathrm{N}) ; c$, the crack length from the centre of the indentation to the crack tip (m); $a$, a half of the indentation diagonal $(\mathrm{m}) ; l$, the crack length $(c-a)$ measured from the vertices of the indentation to the crack tip (m); $T$, the total crack length (m): $T=l_{1}+l_{2}+l_{3}+l_{4} ; E$, Young's modulus (GPa); $H V$, the Vickers hardness (GPa).

The cumulative distribution function that gives the probability of failure $P$ at the fracture toughness $K_{\text {Ic }}$ is expressed by the following equation:

$$
P=1-\exp \left[-\left(\frac{K_{\mathrm{Ic}}}{K_{\mathrm{Ic} 0}}\right)^{\mathrm{m}}\right]
$$

where $P$ is the probability of a failure at the fracture toughness $K_{\mathrm{Ic}}, m$ and $K_{\mathrm{Ic} 0}$ are the Weibull modulus and the scale parameter, respectively. The scale parameter $K_{\mathrm{Ic} 0}$ describes the fracture toughness level that causes failure in $63.2 \%$ of the samples $(P=1-1 / \mathrm{e}=0.632), m$ is the Weibull modulus which gives an indication of fracture toughness data scattering. A higher value of $m$ indicates a smaller variation in the examined property and a high degree of material homogeneity.

\section{Results and discussion}

The microstructure of the Y-TZP dental ceramics at $15000 \times$ magnification is shown in Fig. 2. The scanning electron micrograph shows a fine grained microstructure without pores. 
Sintered samples of the Y-TZP dental ceramics had grain sizes of $425 \pm 137 \mathrm{~nm}$ (mean value \pm standard deviation).

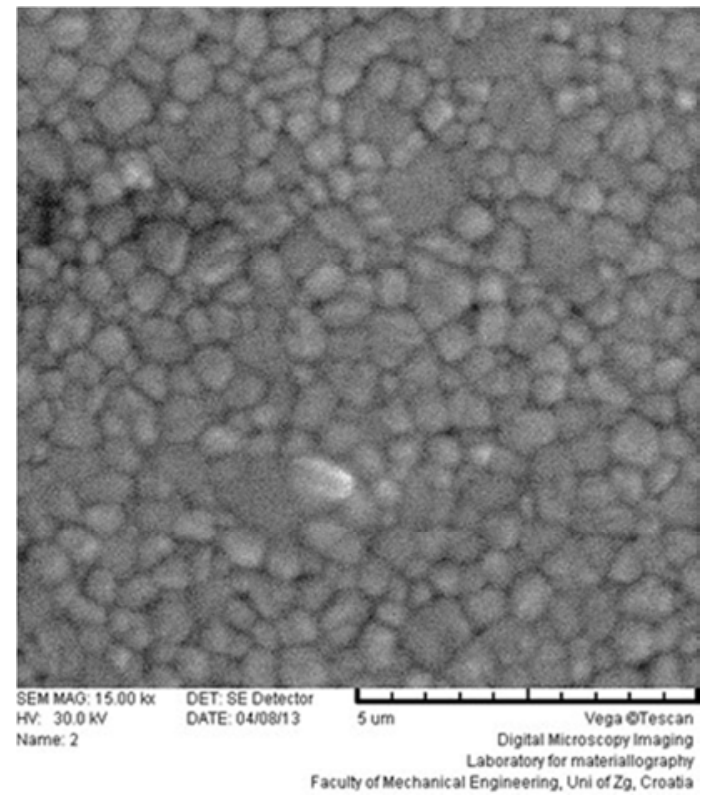

Fig. 2 Scanning electron micrograph of the Y-TZP dental ceramics

The values of the Vickers hardness, the length of indentation diagonal, and the length of cracks measured under different test loads are summarized in Table 3.

Table 3 Statistical analysis of the Vickers hardness $(H V)$, the diagonal half length $(a)$ and the crack half length (c) of Y-TZP dental ceramics (mean values \pm standard deviation).

\begin{tabular}{|l|c|c|c|c|c|}
\hline$F, \mathrm{~N}$ & $N$ & $H V$ & $a, \mu \mathrm{m}$ & $c, \mu \mathrm{m}$ & $c / a$ \\
\hline 29.42 & 30 & $1379 \pm 28$ & $31.7 \pm 0.3$ & $54.3 \pm 1.7$ & 1.71 \\
\hline 49.03 & 30 & $1344 \pm 23$ & $41.5 \pm 0.4$ & $82.7 \pm 1.6$ & 1.99 \\
\hline 196.13 & 30 & $1345 \pm 14$ & $83.0 \pm 0.4$ & $209.6 \pm 7.9$ & 2.53 \\
\hline 294.20 & 30 & $1337 \pm 10$ & $102.0 \pm 0.4$ & $282.8 \pm 5.6$ & 2.77 \\
\hline
\end{tabular}

Major difficulties in determining Vickers indentation fracture toughness values precisely are: identification of the type of formed cracks, precise measurements of the crack length, and application of a suitable model (equation). Fig. 3 illustrates a Vickers indentation with four cracks radiating from the vertices of the indentation as a consequence of applied load. There is no extensive lateral cracking or spalling around the indentations. The area surrounding the Vickers indentation is free from multiple cracking and the crack length was easily measured.

At least two types of cracks are produced by a Vickers indenter, i.e. the Palmqvist crack and the radial-median or half-penny crack [32,33]. Generally, in a tough material, Palmqvist cracks occur. However, most materials will exhibit both crack systems, depending on the applied load $[32,33]$. In a number of brittle materials, Palmqvist cracks were formed in the low-load regime [22]. On the other hand, Palmqvist cracks were formed only at high loads in fairly tough materials, such as WC-Co composites with more than $6 \mathrm{wt}$. \% of Co [23]. There are two ways to identify the crack system present in the analysed material. One way is the verification of the $c / a$ ratio, where $c$ is the crack length from the centre of the indentation to the crack tip and $a$ is a half of the indentation diagonal, Fig. 1, Table 3. If the ratio is less than 
2.5 , then the material shows the Palmqvist crack system [21-23,33]. The other way to differentiate between the two types of crack systems is to polish the surface layers away. The radial-median crack system will always remain connected to the inverted pyramid of the indentation, while Palmqvist cracks will be detached from the indentation [32,33], as shown in Fig. 4. According to both approaches, Palmqvist cracks were observed at lower indentation loads $(29.42 \mathrm{~N}$ and $49.03 \mathrm{~N})$, i.e. the $c / a$ ratio was less than 2.5 (Table 3 ) and, after polishing, the cracks were not connected to the inverted pyramid of the indentation (Fig. 4A and 4B). At higher indentation loads (196.13 $\mathrm{N}$ and $294.20 \mathrm{~N})$ radial-median cracks were confirmed by the values of the $c / a$ ratio higher than 2.5 (Table 3 ) and by the cracks which, after polishing, were still connected to the inverted pyramid of the indentation (Fig. 4C and 4D). When different equations are applied to estimate fracture resistance under different indentation loads, the fracture resistance varies with the crack length within the same material. This was shown by the application of approximation models of Casellas, Palmqvist, Shetty et al., Niihara et al., Anstis, Evans and Charles, Tanaka, Lankford, as well as Niihara, Morena and Hasselman, which take into consideration Young's modulus, the applied indentation load, the indentation size, as well as the crack size.

To define the crack system, indented samples were polished repeatedly, using $6 \mu \mathrm{m}$ diamond as an abrasive. The Palmqvist and radial-median cracks developed under different applied loads, Fig. 4. At the lower indentation loads of $29.42 \mathrm{~N}$ and $49.03 \mathrm{~N}$, Palmqvist cracks were observed. Palmqvist cracks were not connected to the inverted pyramid of the indentation as it is clearly discerned in Fig. 4A and 4B. At higher indentation loads, i.e. 196.13 N and $294.20 \mathrm{~N}$, radial-median cracks were confirmed by the cracks which, after polishing, were still connected to the inverted pyramid of the indentation, Fig. 4C and 4D.
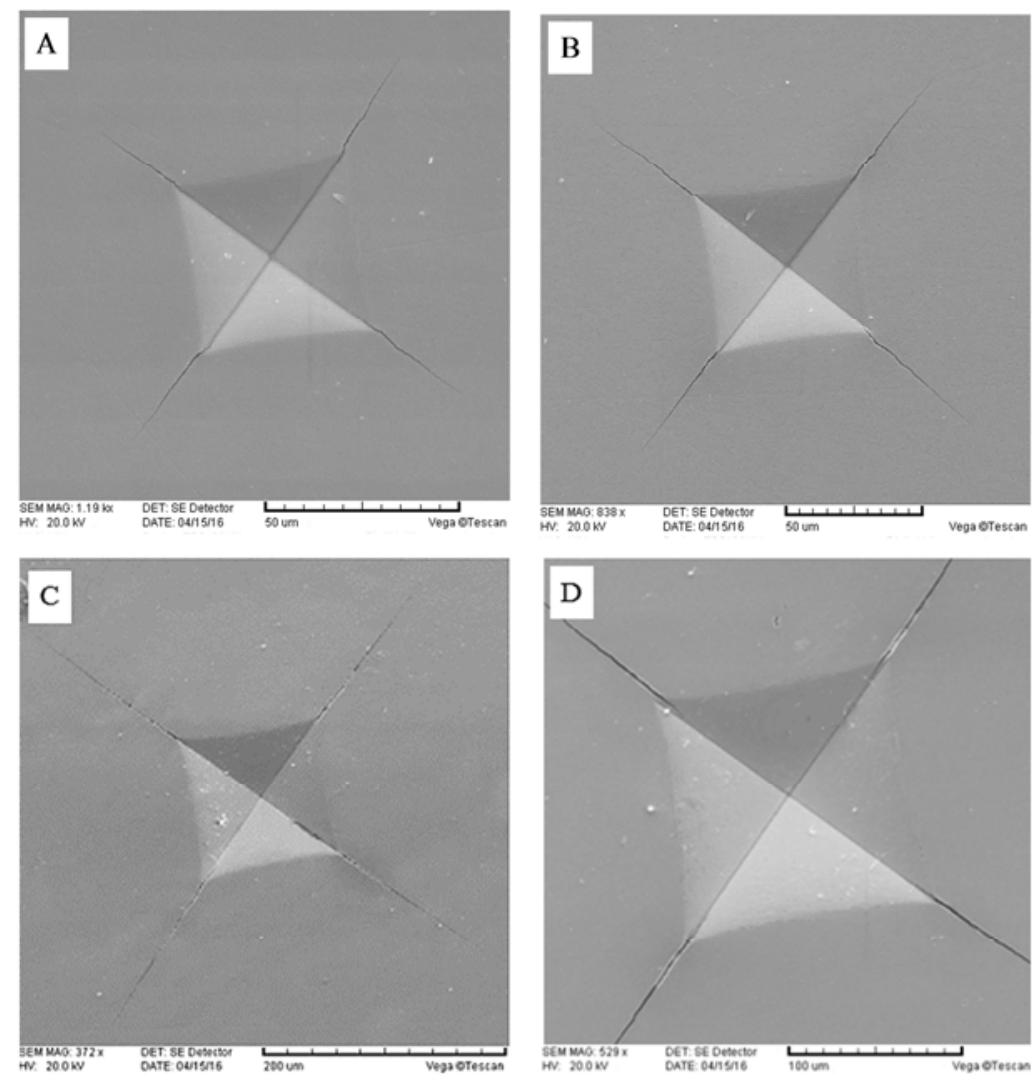

Fig. 3 SEM micrograph of the Vickers indentation and cracks at test loads of (A) $29.42 \mathrm{~N}$, (B) $49.03 \mathrm{~N}$, (C) 196.13 N, and (D) $294.20 \mathrm{~N}$ 

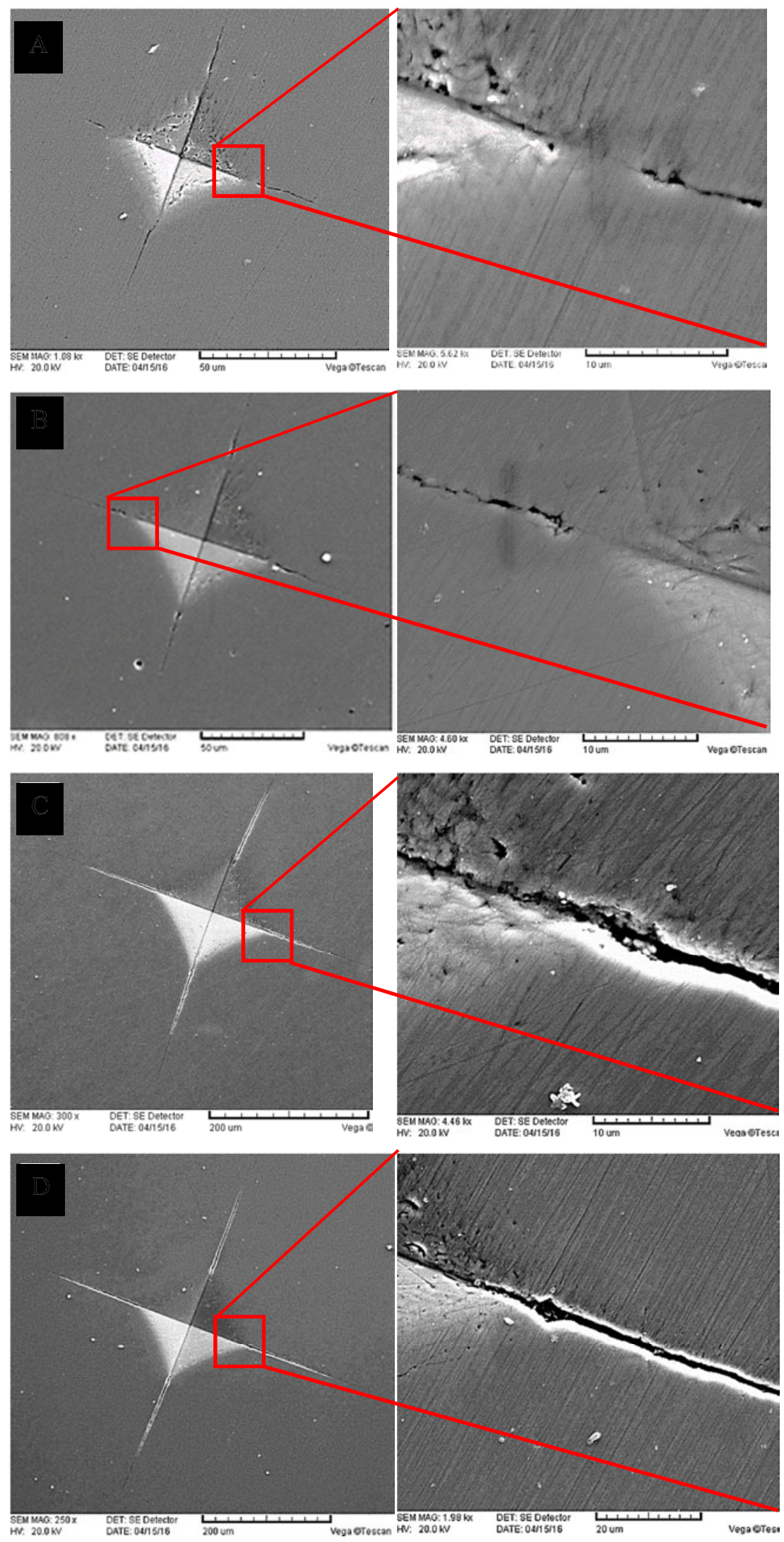

Fig. 4 SEM micrograph of (A, B) the Palmqvist and (C, D) radial-median cracks at test loads of (A) 29.42 N, (B) $49.03 \mathrm{~N}$, (C) $196.13 \mathrm{~N}$, and (D) $294.20 \mathrm{~N}$, after polishing 
The cracks that originated from the Vickers indentations were used to compute fracture toughness by the VIF method, using equations (2) to (10) proposed by Casellas, Palmqvist, Shetty et al., Niihara et al., Anstis, Evans and Charles, Tanaka, Lankford, as well as Niihara, Morena and Hasselman. For Young's modulus E, a value of $210 \mathrm{GPa}$ was assumed [21]. The results of VIF measurements and Weibull parameters are summarized in Table 4.

Table 4 Statistical analysis of the indentation fracture toughness $\left(K_{\mathrm{Ic}}\right)$ of Y-TZP dental ceramics as a function of test load, according to different equations

\begin{tabular}{|c|c|c|c|c|c|c|c|c|}
\hline \multirow[b]{2}{*}{ Equation } & \multirow[b]{2}{*}{$F, \mathrm{~N}$} & \multicolumn{4}{|c|}{$K_{\mathrm{Ic}}, \mathrm{MPa} \mathrm{m}^{1 / 2}$} & \multicolumn{2}{|c|}{$\begin{array}{c}\text { Weibull } \\
\text { parameters }\end{array}$} & \multirow[t]{2}{*}{$R^{2}$} \\
\hline & & average & std. dev. & Min. & Max. & $K_{\text {Ic0 }}$ & $m$ & \\
\hline \multicolumn{9}{|c|}{ Palmqvist crack system } \\
\hline \multirow{2}{*}{ Casellas } & 29.42 & 6.98 & 0.34 & 6.30 & 7.74 & 7.13 & 24.5 & 0.911 \\
\hline & 49.03 & 6.25 & 0.16 & 5.96 & 6.50 & 6.33 & 47.9 & 0.944 \\
\hline \multirow{2}{*}{ Palmqvist } & 29.42 & 5.90 & 0.24 & 5.40 & 6.38 & 6.01 & 30.3 & 0.929 \\
\hline & 49.03 & 5.55 & 0.12 & 5.31 & 5.77 & 5.61 & 54.8 & 0.958 \\
\hline \multirow{2}{*}{$\begin{array}{l}\text { Shetty et } \\
\text { al. }\end{array}$} & 29.42 & 6.25 & 0.25 & 5.71 & 6.75 & 6.36 & 30.4 & 0.930 \\
\hline & 49.03 & 5.88 & 0.13 & 5.62 & 6.10 & 5.94 & 55.5 & 0.960 \\
\hline \multirow{2}{*}{$\begin{array}{l}\text { Niihara et } \\
\text { al. }\end{array}$} & 29.42 & 5.22 & 0.21 & 4.81 & 5.71 & 5.32 & 30.0 & 0.904 \\
\hline & 49.03 & 4.96 & 0.09 & 4.79 & 5.10 & 5.00 & 66.3 & 0.944 \\
\hline \multicolumn{9}{|c|}{ Radial-median crack system } \\
\hline \multirow{2}{*}{ Anstis } & 196.13 & 4.14 & 0.23 & 3.67 & 4.74 & 4.24 & 21.1 & 0.869 \\
\hline & 294.20 & 3.96 & 0.12 & 3.74 & 4.26 & 4.02 & 39.4 & 0.847 \\
\hline \multirow{2}{*}{$\begin{array}{l}\text { Evans and } \\
\text { Charles }\end{array}$} & 196.13 & 4.87 & 0.28 & 4.30 & 5.60 & 5.00 & 20.4 & 0.870 \\
\hline & 294.20 & 4.65 & 0.14 & 4.39 & 5.04 & 4.72 & 38.6 & 0.851 \\
\hline \multirow{2}{*}{ Tanaka } & 196.13 & 4.70 & 0.27 & 4.15 & 5.40 & 4.82 & 20.4 & 0.866 \\
\hline & 294.20 & 4.49 & 0.13 & 4.23 & 4.86 & 4.55 & 38.7 & 0.852 \\
\hline \multirow{2}{*}{$\begin{array}{l}\text { Niihara, } \\
\text { Morena } \\
\text { and } \\
\text { Hasselman }\end{array}$} & 196.13 & 6.06 & 0.34 & 5.37 & 6.95 & 6.22 & 20.9 & 0.869 \\
\hline & 294.20 & 5.80 & 0.17 & 5.47 & 6.25 & 5.88 & 39.0 & 0.852 \\
\hline \multicolumn{9}{|c|}{ Crack system of any kind } \\
\hline \multirow{4}{*}{ Lankford } & 29.42 & 7.73 & 0.36 & 6.97 & 8.45 & 7.89 & 26.1 & 0.939 \\
\hline & 49.03 & 6.87 & 0.18 & 6.51 & 7.15 & 6.95 & 45.3 & 0.946 \\
\hline & 196.13 & 6.72 & 0.40 & 5.93 & 7.75 & 6.90 & 20.1 & 0.868 \\
\hline & 294.20 & 6.40 & 0.20 & 6.02 & 6.92 & 6.50 & 37.5 & 0.849 \\
\hline
\end{tabular}

Figs. 5 and 6 show the dependence of the indentation fracture toughness values on the applied load, calculated using equations according to Casellas (2), Palmqvist (3), Shetty et al. (4) and Niihara et al. (5) for the Palmqvist crack system and Anstis (6), Evans and Charles (7), Tanaka (8), Niihara, Morena and Hasselman (9) for the median crack profile or the Lankford model (10) for both types of cracks. 


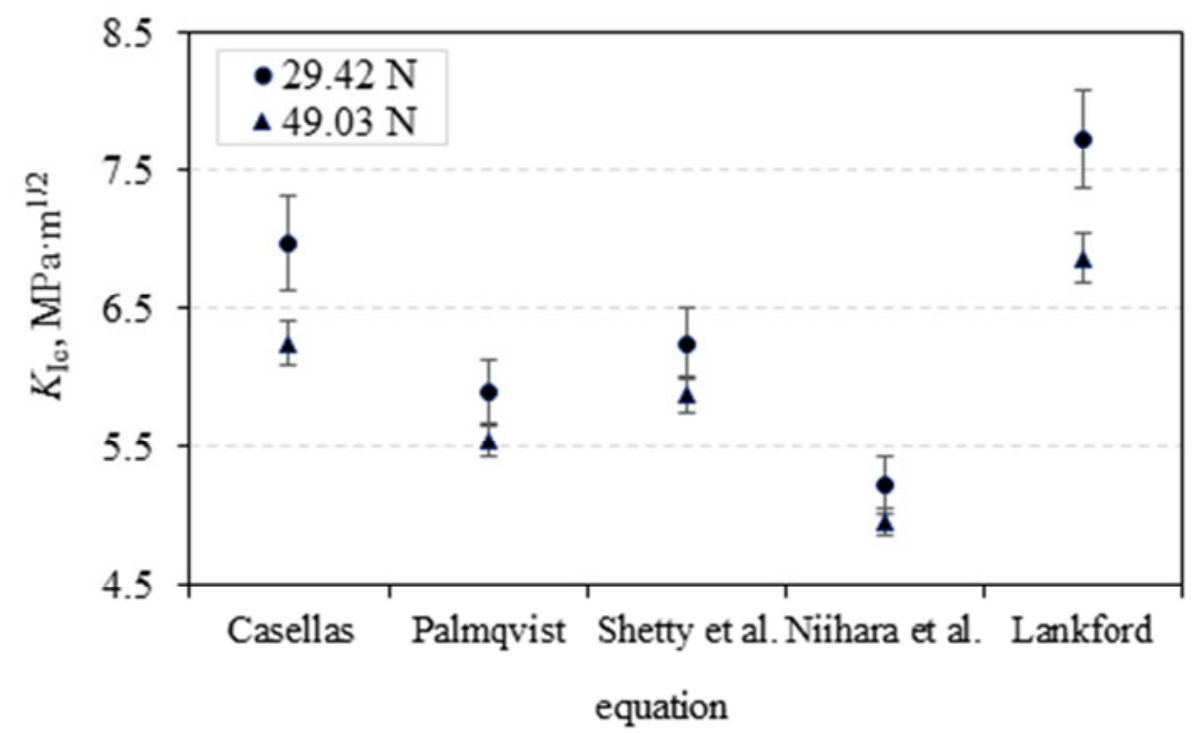

Fig. 5 Comparison of fracture toughness values, measured at $29.42 \mathrm{~N}$ and $49.03 \mathrm{~N}$, calculated using equations for the Palmqvist crack system

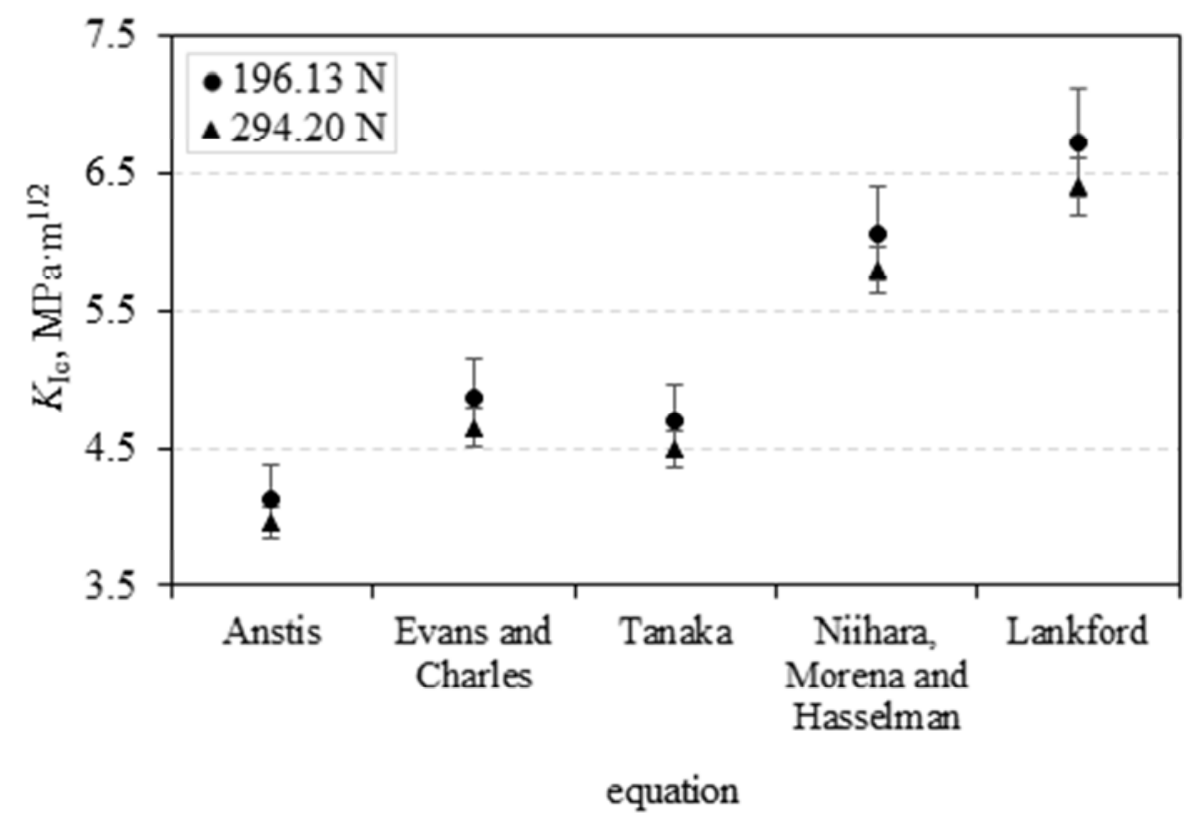

Fig. 6 Comparison of fracture toughness values, measured at 196.13 N and 294.20 N, calculated using equations for the radial-median crack system

The Weibull modulus $m$ and the scale parameter $K_{\text {Ic0 }}$ are obtained by the linear regression analysis according to the following equation:

$$
\ln \ln \left(\frac{1}{1-P}\right)=m \ln K_{\mathrm{Ic}}-m \ln K_{\mathrm{Ic} 0}
$$

From Figs. 7 and 8, one can see that a straight line can be obtained by plotting $\ln \ln \left(\frac{1}{1-P}\right)$ against $\ln K_{\text {Ic }}$. The slope presents $m$ and the intercept $m \ln K_{\text {Ic0. As it can be seen }}$ from Table 4 and Figs. 7 and 8, the Weibull parameter $m$ varies from 20.1 (Lankford, $F=196.13 \mathrm{~N}$ ) to 66.3 (Niihara et al., $F=49.03 \mathrm{~N}$ ). The correlation coefficient varies between 
D. Ćorić, L. Ćurković, M. Majić Renjo
Statistical Analysis of Vickers Indentation

Fracture Toughness of Y-TZP Ceramics

0.847 and 0.960 , depending on the applied model and indentation load. The scale parameter $K_{\text {Ic0 }}$ is estimated from the intercept $\left(m \ln K_{\text {Ic0 }}\right)$ :

$$
K_{\text {Ic } 0}=\exp \left(-\left(m \ln K_{\text {Ic } 0}\right) / m\right)
$$

The obtained values of $m$ and $K_{\mathrm{Ic} 0}$ are inserted into equation (11).
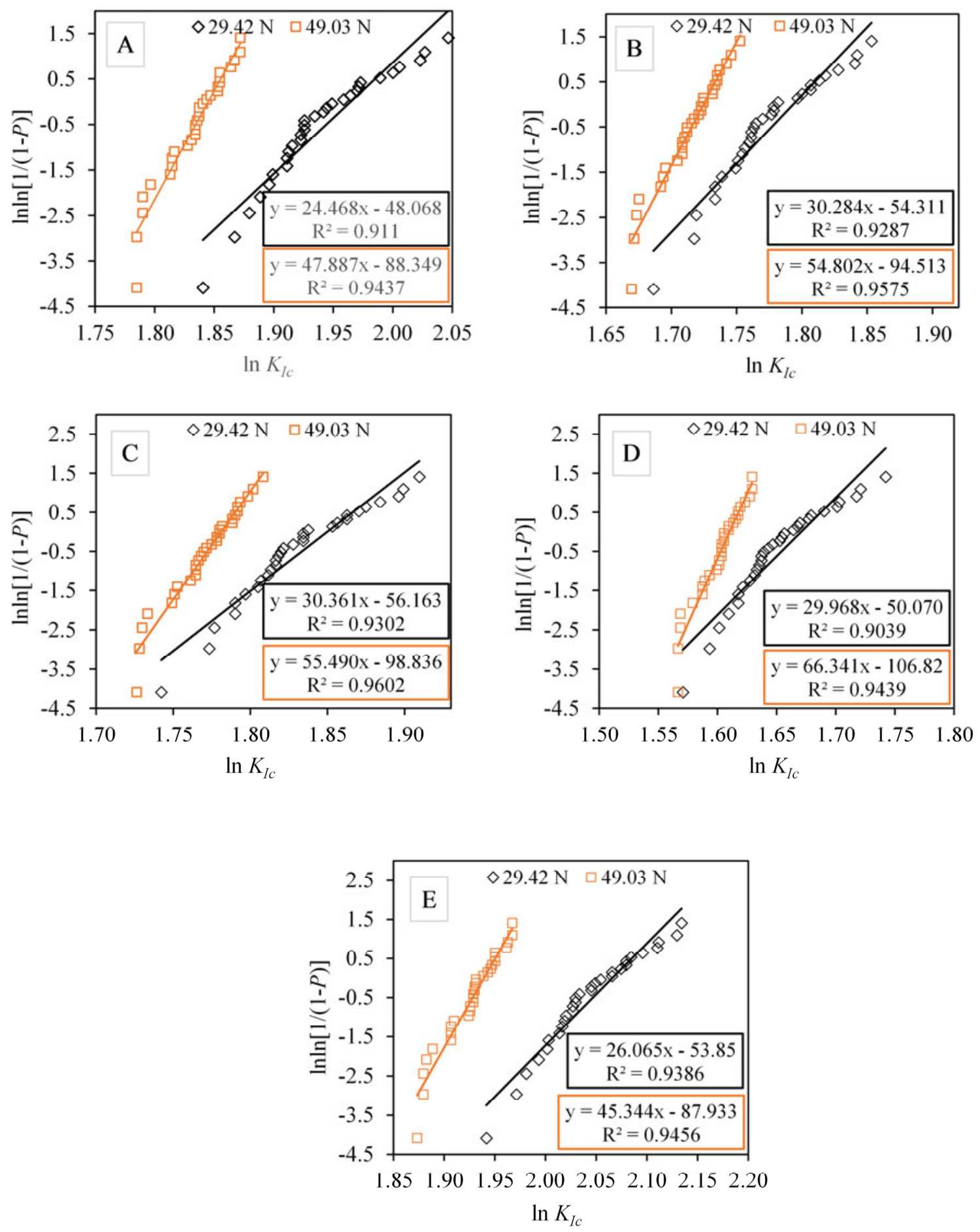

Fig. 7 Weibull plot of the fracture toughness at test loads of $29.42 \mathrm{~N}$ and $49.03 \mathrm{~N}$ : (A) Casellas, (B) Palmqvist, (C) Shetty et al., (D) Niihara et al., (E) Lankford model 

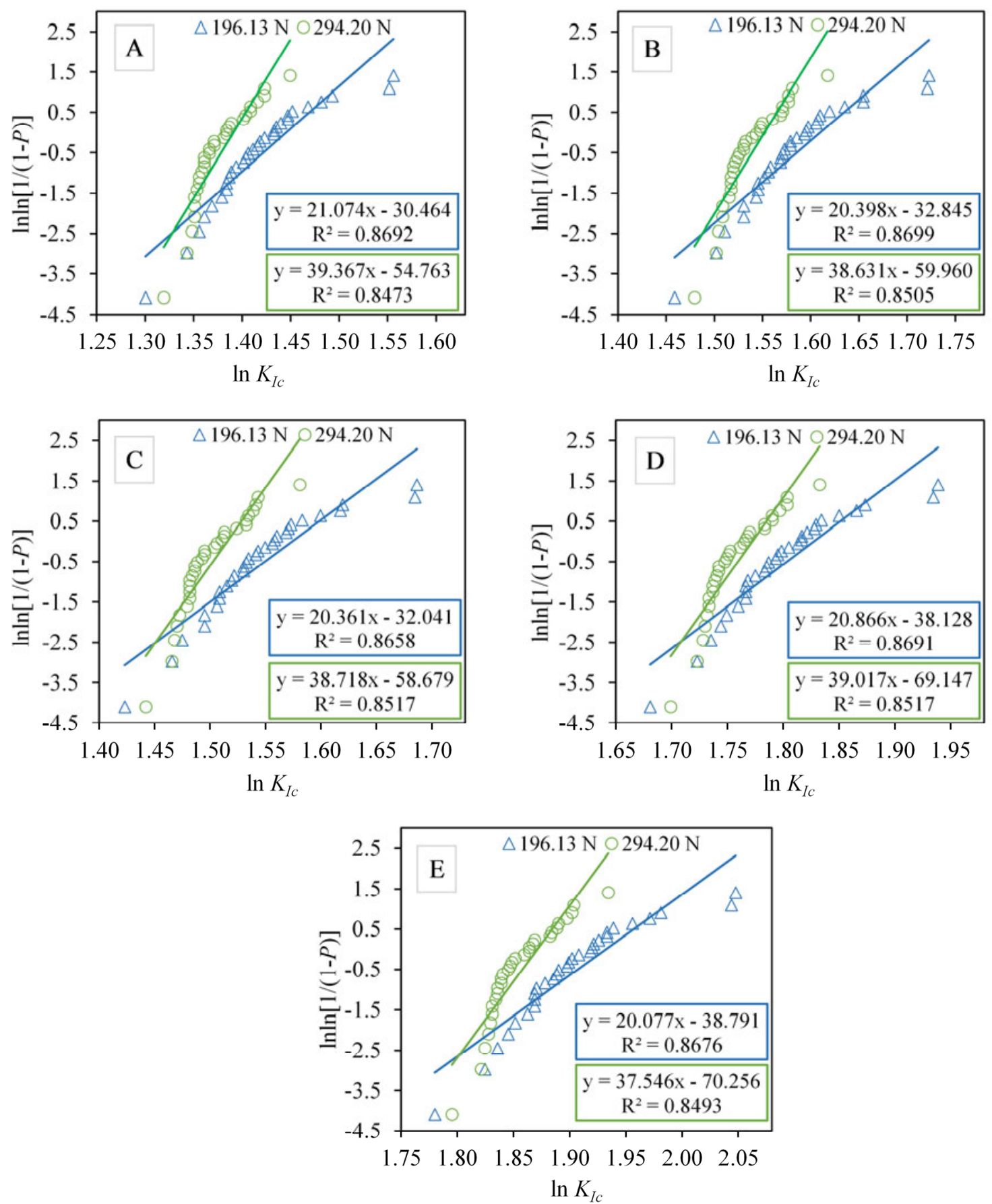

Fig. 8 Weibull plot of the fracture toughness at test loads 196.13 N and 294.20 N: (A) Anstis, (B) Evans and Charles, (C) Tanaka, (D) Niihara, Morena and Hasselman, (E) Lankford model

Fig. 9 shows a cumulative distribution function for the normalized fracture toughness according to Casellas, Palmqvist, Shetty et al., Niihara et al. and Lankford determined by the loads $29.42 \mathrm{~N}$ and $49.03 \mathrm{~N}$, whereas Fig. 10 refers to a cumulative distribution function for the normalized fracture toughness according to Anstis, Evans and Charles, Tanaka, Lankford, Niihara, Morena and Hasselman calculated by the test loads $196.13 \mathrm{~N}$ and 294.20 N. The fracture toughness values are ranked from the minimum to the maximum value and each value is assigned a probability of failure $(P)$ based on its ranking $i$, with $i$ ranging from 1 to $n$, where $n$ is the number of measurements of fracture toughness (in this case $n=30$ ). In the construction of this plot, the thirty measured $K_{\mathrm{Ic}}$ data were normalized by their average value $K_{\text {Ic,av. }}$ 
D. Ćorić, L. Ćurković, M. Majić Renjo
Statistical Analysis of Vickers Indentation

Fracture Toughness of Y-TZP Ceramics

The cumulative probability of failure $(P)$ is calculated using the following equation [26,29]:

$$
P_{i}=\frac{i-0.5}{n}
$$

where $i$ is the rank and $n$ is the total number of data. The shape of the cumulative probability function is shown in Figs. 9 and 10.
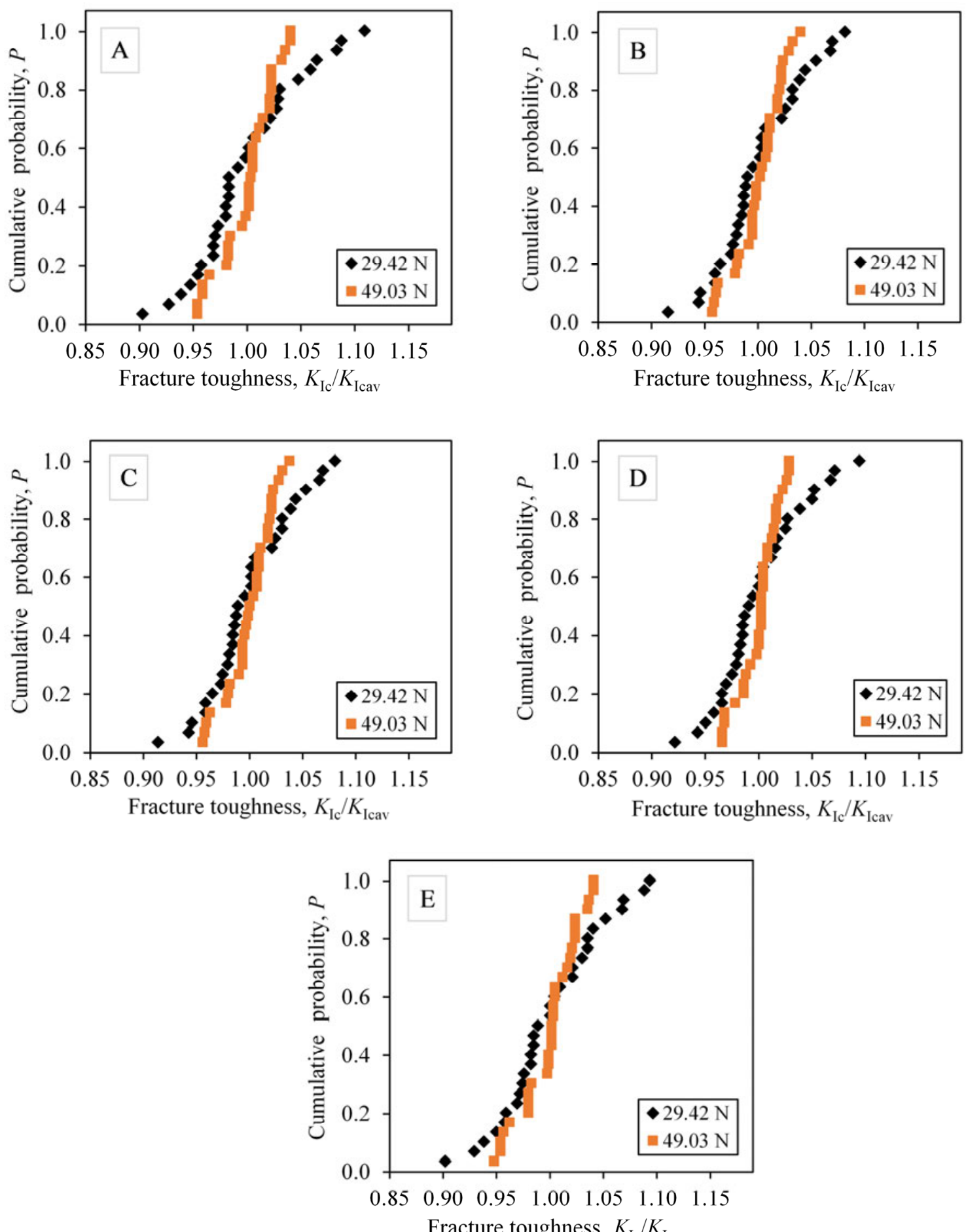

Fig. 9 Cumulative probability function of the fracture toughness at the test loads of $29.42 \mathrm{~N}$ and $49.03 \mathrm{~N}$ : (A) Casellas, (B) Palmqvist, (C) Shetty et al., (D) Niihara et al., (E) Lankford model 

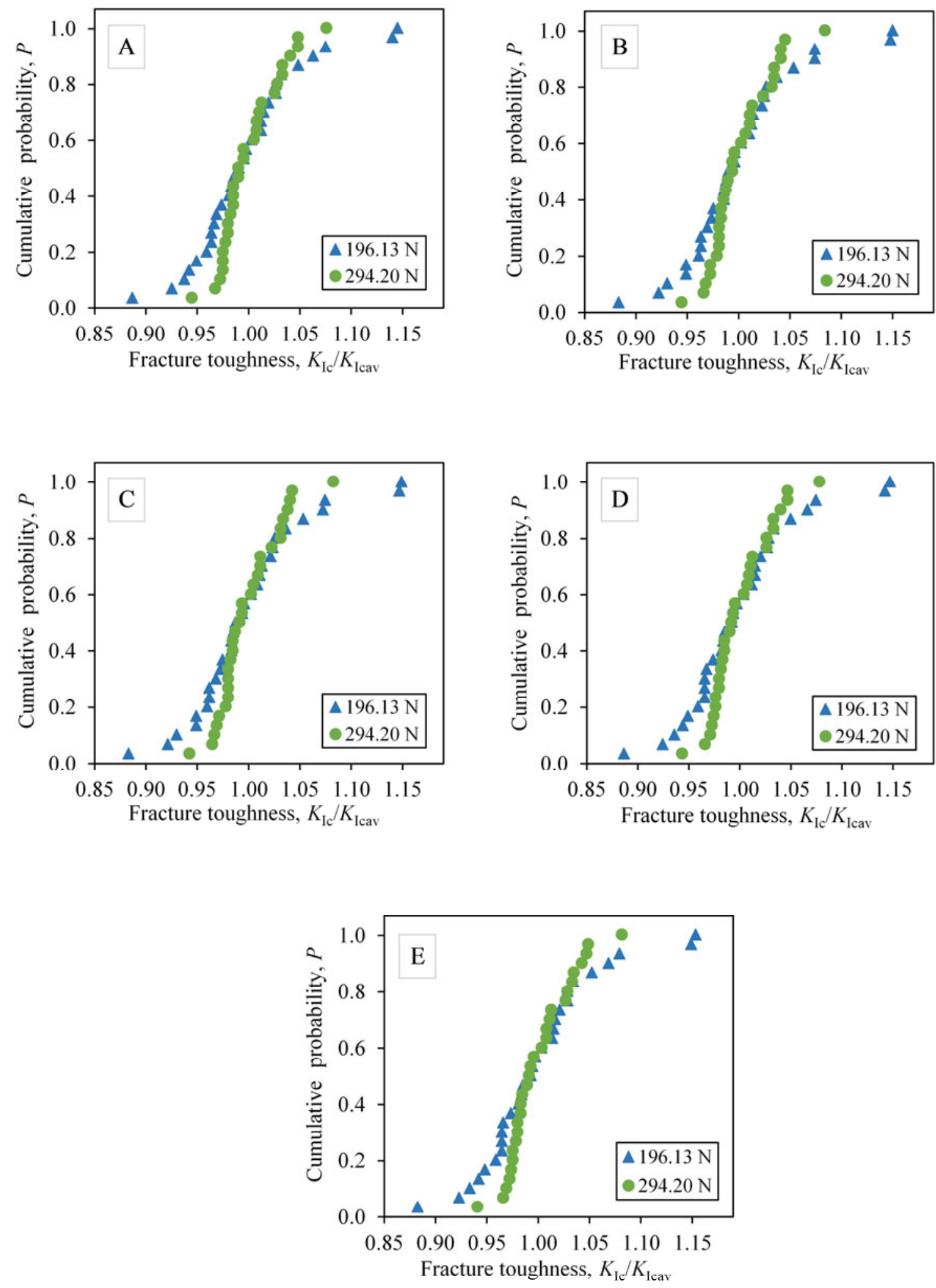

Fig. 10 Cumulative probability function of the fracture toughness at the applied load of $196.13 \mathrm{~N}$ and $294.20 \mathrm{~N}$ : (A) Anstis, (B) Evans and Charles, (C) Tanaka, (D) Niihara, Morena and Hasselman, (E) Lankford model 
Generally, fracture toughness values obtained by the considered models showed a decrease in the observed fracture toughness when the applied load was increased (Figs. 5 and 6). Depending on the applied load and the mathematical model, the calculated fracture toughness values of the investigated Y-TZP dental ceramics vary in the range from 4.96 to $7.73 \mathrm{MPa} \mathrm{m}^{1 / 2}$ for the Palmqvist crack and from 3.96 to $6.72 \mathrm{MPa} \mathrm{m}^{1 / 2}$ for the radial-median crack profile. The lowest fracture toughness value was calculated by the Anstis model under the load of $294.20 \mathrm{~N}$, while the highest value resulted from the Lankford model under the load of $29.42 \mathrm{~N}$.

\section{Conclusion}

The results presented in this paper can be summarized as follows:

- Hardness values of the investigated Y-TZP dental ceramics vary with the applied indentation load in the low-load regime.

- The fracture toughness values of Y-TZP dental ceramics depend on the applied indentation load, the morphology of the indentation cracking, as well as on the model selected for the fracture resistance calculation.

- Y-TZP dental ceramics has exhibited the Palmqvist crack system under lower indentation loads, i.e. $29.42 \mathrm{~N}$ and $49.03 \mathrm{~N}$, which induce shallow Palmqvist cracks, radially spreading from the vertices of the indentation. This is in agreement with the obtained value of the $c / a$ ratio, which is less than 2.5. Higher indentation loads, i.e. $196.13 \mathrm{~N}$ and $294.20 \mathrm{~N}$, cause the merging of the cracks into the radialmedian shape, which is in agreement with the obtained values of the $c / a$ ratio higher than 2.5 .

- Two-parameter Weibull distribution has been used successfully to describe the statistical variability of fracture toughness according to Casellas, Palmqvist, Shetty et al., Niihara et al., Anstis, Evans and Charles, Tanaka, Lankford, Niihara, Morena and Hasselman models at different indentation loads. Values of the Weibull modulus $(m)$ very in the range from 20.4 (Evans and Charles, Tanaka, $F=196.13 \mathrm{~N}$ ) to 66.3 (Niihara et al. $F=49.03 \mathrm{~N}$ ). Generally, the high values of Weibull modulus indicate very little data scattering for a particular model and applied load, as well as the homogeneity of the tested material.

\section{REFERENCES}

[1] Green DJ, Hannink RHJ, Swain MV. Transformation Toughening of Ceramics, Florida: CRC Press, 1989.

[2] Zhang X, Deng Z, Ren Y, Chen G, Liu W, Zhang G. Laser-Induced Deterioration Grinding of Zirconium Oxide (ZrO2) - Generation of Layer Patterns and Performance Evaluation. Strojniški vestnik - Journal of Mechanical Engineering 2015;61:689-697. DOI:10.5545/sv-jme.2015.2794

[3] McMeeking R, Evans AG. Mechanics of transformation- toughening in brittle materials. J Am Ceram Soc 1982;65:242-246. DOI:10.1111/j.1151-2916.1982.tb10426.x

[4] Guazzato M, Albakry M, Ringer SP, Swain MV. Strength, fracture toughness and microstructure of a selection of all-ceramic materials. Part II. Zirconia-based dental ceramics. Dent Mater 2005;20:449-456. DOI:10.1016/j.dental.2003.05.002

[5] Camposilvan E, Garcia Marro F, Mestra A, Anglada M. Enhanced reliability of yttria-stabilized zirconia for dental applications. Acta Biomater 2015;17:36-46. DOI:10.1016/j.actbio.2015.01.023

[6] Majić Renjo M, Ćurković L, Štefančić S, Ćorić D. Indentation size effect of Y-TZP dental ceramics. Dent Mater 2014;30:e371-376. DOI:10.1016/j.dental.2014.08.367 
[7] Evans AG, Charles EA. Fracture toughness determinations by indentation. J Am Ceram Soc 1976;59:371-372. DOI:10.1111/j.1151-2916.1976.tb10991.x

[8] Casellas D, Feder A, Llanes L, Anglada M. Fracture toughness and mechanical strength of Y-TZP/PSZ ceramics. Scripta Mater 2001;45:213-220. DOI:10.1016/S1359-6462(01)01020-X

[9] Živko-Babić J, Carek A, Jakovac M. Zirconia ceramics in dental prosthodontics. Acta Stomat Croat 2005;39:19-23.

[10] Freimann SW. Brittle fracture behavior of ceramics. Am Ceram Soc Bulletin 1988;67:392-402.

[11] Pabst RF, Kromp K, Popp G. Fracture toughness - measurement and interpretation. Proc Brit Cer Soc 1982;32:89-94.

[12] Harada K, Shinya A, Yokoyama D. Effect of loading conditions on the fracture toughness of zirconia. J Orthod Res 2013;57:82-87. DOI:10.1016/j.jpor.2013.01.005

[13] Anstis GR, Chantikul P, Lawn BR, Marshall DP. A critical Evaluation of Indentation Techniques for Measuring Fracture Toughness: I, Direct Crack Measurements. J Am Ceram Soc 1981; 64(9): 533-538. DOI:10.1111/j.1151-2916.1981.tb10320.x

[14] Chantikul P, Anstis GR, Lawn B, Marshall DB. A critical Evaluation of Indentation Techniques for Measuring Fracture Toughness: II, Strength Method. J Am Ceram Soc 1981; 64(9): 539-543. DOI:10.1111/j.1151-2916.1981.tb10321.x

[15] Nastic A, Merati A, Bielawski M, Bolduc M, Fakolujo O, Nganbe M, Instrumented and Vickers Indentation for the Characterization of Stiffness, Hardness and Toughness of Zirconia Toughened A12O3 and SiC Armor, J Mater Sci Technol 2015; 31(8); 773-783. DOI:10.1016/j.jmst.2015.06.005

[16] Strecker K, Ribeiro S, Hoffmann MJ. Fracture toughness measurements of LPS-SiC: a comparison of the indentation technique and the SEVNB method. Mat Res 2005;8:121-124. DOI:10.1590/S1516-14392005000200004

[17] Quinn GD. Fracture toughness of ceramics by the Vickers indentation crack length method. Ceram Eng Sci Proc, John Wiley \& Sons, Inc., New Jersey, 2007, 45-62.

[18] Casellas D, Nagl MM, Llanes L, Anglada M. Microstructural coarsening of zirconia-toughened alumina composites. J Am Ceram Soc 2005;88 (7):1958-1963. DOI:10.1111/j.1551-2916.2005.00374.x

[19] A. Şakar -Deliormanli, M. Güden, Microhardness and fracture toughness of dental materials by indentation method. J Biomed Mater Res B Appl Biomater 2006;76:257-64. DOI:10.1002/jbm.b.30371

[20] ASTM E112 - 13, Standard Test Methods for Determining Average Grain Size

[21] Corrêa de Sá e Benevides de Moraes MC, Elias CN, Filho JD, Guimarães de Oliveira L. Mechanical properties of alumina-zirconia composites for ceramic abutments. Mat Res 2004;7:643-649. DOI:10.1590/S1516-14392004000400021

[22] Niihara K, Morena R, Hasselman DPH. Evaluation of KIc of brittle solids by the indentation method with low crack-to-indent ratios. J Mat Sci Letters 1982;1(1):13-16. DOI:10.1007/BF00724706

[23] Bhat M, Kaur B, Kumar R, et al. Effect of ion irradiation on dielectric and mechanical characteristics of ErFeO3 single crystals. Nucl Instrum Meth B 2005; 234:494-508. DOI:10.1016/j.nimb.2005.01.119

[24] Weibull W. A Statistical Distribution Function of Wide Applicability. J Appl Mech 1951;18:293-305.

[25] Lu C, Danzer R, Fishcer D. Fracture statistics of brittle materials: Weibull or normal distribution. Phys Rev E 2002;65:067102. DOI:10.1103/PhysRevE.65.067102

[26] Danzer R, Supancic P, Pascual J, Lube T. Fracture statistic of ceramics-Weibull statistics and derivations from Weibull statistics. Engineering of Fracture Mechanics 2007;74: 2919-2932. DOI:10.1016/j.engfracmech.2006.05.028

[27] Saghafi A, Mirhabibi AR, Yari GH. Improved linear regression method for estimating Weibull parameters. Theor Appl Fract Mech 2009;52:2-180. DOI:10.1016/j.tafmec.2009.09.007

[28] Langlois R. Estimation of Weibull parameters. J Mater Sci Letters 1991; 10:1049-1051. DOI:10.1007/BF00720121

[29] Wu D, Jiang H. Comment on "A new probability index for estimating Weibull modulus for ceramics with the last-square method". J Mater Sci 2003;22:1745-1746.

[30] Gong J. A simple method for determining the Weibull estimator. J Mater Sci Letters 1997;16:875-876. DOI:10.1023/A:1018515516659 
D. Ćorić, L. Ćurković,

M. Majić Renjo
Statistical Analysis of Vickers Indentation Fracture Toughness of Y-TZP Ceramics

[31] S. Palmqvist, A method to determine the fracture toughness brittle materials, especially hard metals. Jenkontorets Ann 1957;141:303-307.

[32] Barsoum MW. Fundamentals of Ceramics. Taylor \& Francis Group, New York, 2003, 368-369. DOI: $10.1887 / 0750309024$

[33] Lin JD, Duh JG. Fracture toughness and hardness of ceria and yttria-doped tetragonal zirconia ceramics. Mater Chem Phys 2002;78:253-261. DOI:10.1016/S0254-0584(02)00327-9

Submitted: $\quad 03.10 .2016$

Accepted: $\quad 02.02 .2017$
Danko Ćorić

Lidija Ćurković

Marijana Majić Renjo

marijana.majic@fsb.hr

Faculty of Mechanical Engineering and

Naval Architecture,

Ivana Lučića 5, Zagreb, Croatia 